\title{
Early Childhood Caries- A Review of Its Aetiology, Classification, Consequences, Prevention and Management
}

\author{
Pinky Goswami ${ }^{1}$
}

${ }^{1}$ Department of Dentistry, JMCH, Jorhat, Assam, India.

\section{ABSTRACT}

\section{BACKGROUND}

Early childhood caries (ECC) is a cause of serious concern globally. It is a major oral health problem affecting the primary dentition of infants and toddlers. At first it appears as white spots along the gingival margin of upper primary incisors. As the disease progresses, the white lesions develop into cavities which gradually enlarges resulting in complete loss of the crown. The major risk factors associated with the aetiology of ECC are classified into microbiological factors, dietary factors and environmental factors. In addition to these, several other contributory factors have been identified. Factors like lack of proper feeding practices, poor socioeconomic conditions, illiterate parents and inability to avail dental care can also contribute to the development of ECC. It is important to maintain the primary dentition in a healthy condition as it is essential for chewing, speech, facial beauty, preservation of space and prevention of abnormal habits. The most common immediate consequence of untreated dental caries is dental pain which disturbs the regular activities of children such as talking, eating, sleeping and playing. Severe ECC can lead to functional, aesthetic and psychological disturbances of the child due to early loss of teeth. ECC is not self-limiting and hence requires treatment to remove infection and restore function. The treatment of ECC includes educating and counseling of mothers, fluoride application, oral hygiene measures, dietary guidance and remedial measures. Since oral health constitutes an integral part of general health, ECC if left untreated can lead to far reaching health issues. This review focuses on the prevalence, aetiology, risk factors, preventive strategies and management of ECC.

\section{KEY WORDS}

Early Childhood Caries, Prevalence, Risk Factors.
Corresponding Author: Dr. Pinky Goswami, Assistant Professor, Department of Dentistry, JMCH, Jorhat, Assam, India. E-mail: pinkyjmcjorhat@gmail.com

DOI: 10.14260/jemds/2020/173

Financial or Other Competing Interests: None.

How to Cite This Article:

Goswami P. Early childhood caries- a review of its aetiology, classification, consequences, prevention and management. J. Evolution Med. Dent. Sci. 2020;9(10):798-803, DOI: 10.14260/jemds/2020/173

Submission 27-12-2019, Peer Review 08-02-2020, Acceptance 14-02-2020, Published 09-03-2020.

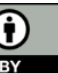




\section{BACKGROUND}

Early Childhood caries is a form of rampant caries affecting the primary dentition of infants and toddlers. Dental caries in pre-school children and toddlers was described by several terms like baby bottle decay or nursing bottle caries. In 1978 the American Academy of Pedodontics and the American Academy of Pediatrics issued a joint statement [1] which stated that improper bottle feeding was responsible for the severe form of caries in toddlers and children. They suggested that to avoid nursing caries, bottle feeding should be stopped after the first birthday. However, over the next few decades it was recognized that improper bottle feeding was not the only causative factor of this caries and a multifactorial aetiology was suggested. In 1994 the Center for Disease Control and Prevention recommended the term early childhood caries to focus attention on the various contributory factors that lead to caries in toddlers and children. Early Childhood Caries is defined as the presence of one or more decayed (cavitated or non-cavitated), missing teeth or filled tooth surfaces in any primary tooth in a preschool child between birth and 71 months of age. In children younger than three years of age any sign of smooth surface caries is an indication of severe early childhood caries. In children between three-years to five-years, severe ECC is recognized by the presence of one or more cavitated or missing teeth or filled tooth surface in primary maxillary anterior teeth. [2]

\section{Clinical Appearance}

In the initial stage of ECC the lesion appears as white opaque spots or as a white band in the cervical third of the maxillary incisors. The initial lesion can also appear around the gingival margin between the interproximal surfaces of teeth or on the palatal surfaces of teeth and in extreme cases at the incisal edge. ${ }^{[3,4]}$ As the condition progresses the enamel surface breaks down and a cavity is created which can turn yellow, brown or black and gradually encircles the neck of the teeth with extensive loss of hard tissue. The initial lesion is subsurface; that is most of the mineral loss occurs beneath a relatively intact enamel surface. The thickness of enamel in primary incisors is less $(<0.5 \mathrm{~mm})$ and the immature enamel of primary teeth is porous and hence more easily dissolved by acids.[5] These two factors contribute to the rapid progression of caries in primary teeth

In advanced cases there may be complete loss of crown structure of maxillary incisors whereas the mandibular incisors remain caries free. This unique pattern of caries distribution in ECC can be attributed to three major factors: the chronology of tooth eruption, the duration of deleterious habit and the pattern of feeding. The maxillary incisors are the earliest to erupt and are most severely affected by the caries process. If the caries process is not arrested the other teeth will be subsequently affected according to their sequence of eruption. During feeding the tongue forms a protective cover over the lower incisors in such a way that except the four mandibular incisors all the other teeth come in contact with the feeding liquid.
The liquid containing fermentable carbohydrate is metabolized by oral bacteria into acids which lowers the salivary $\mathrm{pH}$ leading to demineralization.

\section{Classification}

Several researchers have attempted to develop classification systems for early childhood caries.

1. The first system of classification was given by Wyne in 1999.[6] It was based on the severity and the associated aetiology of ECC. According to this system ECC was classified into three categories:

\begin{tabular}{|c|c|c|}
\hline Category & Characteristics of Carious Lesion & Aetiology \\
\hline $\begin{array}{c}\text { Type I } \\
\text { Mild to } \\
\text { moderate }\end{array}$ & $\begin{array}{c}\text { Isolated carious lesions involving } \\
\text { incisors and/or molars. }\end{array}$ & $\begin{array}{c}\text { The most common causes are } \\
\text { usually a combination of } \\
\text { semisolid/solid diet and lack of } \\
\text { oral hygiene. }\end{array}$ \\
\hline $\begin{array}{c}\text { Type II } \\
\text { Moderate to } \\
\text { severe }\end{array}$ & $\begin{array}{c}\text { The lesions are present on the labial or } \\
\text { lingual surface of maxillary central } \\
\text { incisors. Molar caries may or may not be } \\
\text { present depending on the age of the } \\
\text { child and stage of the disease. The } \\
\text { mandibular incisors remain unaffected }\end{array}$ & $\begin{array}{c}\text { The main cause is usually an } \\
\text { improper use of a feeding } \\
\text { bottle or at-will breast feeding. } \\
\text { or a combination of both, with } \\
\text { or without poor oral hygiene. }\end{array}$ \\
\hline $\begin{array}{c}\text { Type III } \\
\text { Severe or } \\
\text { extreme }\end{array}$ & $\begin{array}{c}\text { In this type the carious lesions affect } \\
\text { almost all teeth including the } \\
\text { mandibular incisors. }\end{array}$ & $\begin{array}{c}\text { The causative factors are a } \\
\text { combination of cariogenic food } \\
\text { substance and poor oral } \\
\text { hygiene. }\end{array}$ \\
\hline \multicolumn{3}{|c|}{ Table 1. Classification of ECC by Wyne } \\
\hline
\end{tabular}

2. A second system of classification was given by Johnston and Meissner based on the pattern of ECC. [7]

\begin{tabular}{|c|c|}
\hline Type I & $\begin{array}{c}\text { Lesions associated with developmental defects } \\
\text { ( pit and fissure defects and hypoplasia ) }\end{array}$ \\
\hline Type II & Smooth surface lesions (Labial- lingual lesions, approximal molar lesions); \\
\hline Type III & $\begin{array}{c}\text { Rampant caries - having caries in 14 out of 20 primary teeth, including at } \\
\text { least one mandibular incisor. }\end{array}$ \\
\hline Table 2 Classification System of ECC Given by Johnston \& Meissner \\
\hline
\end{tabular}

3. Another classification system (not specifically for ECC) is the Caries Analysis System (CAS) given by Ismail and Sohn ${ }^{[8]}$ in 1999 . This system of classification is based on the site of occurrence of the carious lesion. However, this system excludes the buccal and lingual surfaces of the maxillary canines, the buccal, lingual and mesial surfaces of the mandibular canines, and all tooth surfaces of the mandibular incisors.

4. A fourth system of classification was given by Veerkamp and Weerheijm[9] in 1995 based on the stage of development of the dentition and severity of dental caries (initial and cavitated). This classification assumes that dental caries occurs in successive stages starting late in the first year (10 months )and ending in the fourth year of life (48 months).The four stages are referred to as: initial, damaged, deep lesions and traumatic. At each stage a different set of teeth are involved, and dental caries can range from enamel demineralization to cavitation involving enamel and dentin.

In spite of the efforts made to classify ECC lesions clinically; there was an urgent need for a standard system for the diagnosis and reporting of ECC for research purposes. The description of ECC and severe ECC [10] was formulated in 1999 at a workshop in Bethesda. 


\begin{tabular}{|c|c|c|}
\hline $\begin{array}{c}\text { Age } \\
\text { (Months) }\end{array}$ & Early Childhood Caries & Severe ECC \\
\hline $\begin{array}{c}\text { Less than } \\
12 \text { months }\end{array}$ & $\begin{array}{c}1 \text { or more decayed, missing } \\
\text { or filled surfaces }\end{array}$ & $\begin{array}{c}\text { 1 or more decayed, missing or filled tooth } \\
\text { surface }\end{array}$ \\
\hline $\begin{array}{c}12-23 \\
\text { months }\end{array}$ & $\begin{array}{c}1 \text { or more decayed, missing } \\
\text { or filled surfaces }\end{array}$ & $\begin{array}{c}1 \text { or more decayed, missing or filled } \\
\text { smooth surfaces }\end{array}$ \\
\hline $\begin{array}{c}24-35 \\
\text { months }\end{array}$ & $\begin{array}{c}1 \text { or more decayed, missing } \\
\text { or filled surfaces }\end{array}$ & $\begin{array}{c}1 \text { or more decayed, missing or filled tooth } \\
\text { surfaces }\end{array}$ \\
\hline $\begin{array}{c}36-47 \\
\text { months }\end{array}$ & $\begin{array}{c}1 \text { or more decayed, missing } \\
\text { or filled surfaces. }\end{array}$ & $\begin{array}{c}\text { 1 or more cavitated, filled or missing (due } \\
\text { to caries) smooth surfaces in primary } \\
\text { maxillary anterior teeth or DMFS score }>4\end{array}$ \\
\hline $\begin{array}{c}48-59 \\
\text { months }\end{array}$ & $\begin{array}{c}1 \text { or more decayed, missing } \\
\text { or filled surfaces }\end{array}$ & $\begin{array}{c}\text { 1 or more cavitated, filled or missing (due } \\
\text { to caries) smooth surfaces in primary } \\
\text { maxillary anterior teeth or DMFS score }>5\end{array}$ \\
\hline $\begin{array}{c}60-71 \\
\text { months }\end{array}$ & $\begin{array}{c}1 \text { or more decayed, missing } \\
\text { or filled surfaces }\end{array}$ & $\begin{array}{c}1 \text { or more cavitated, filled or missing (due } \\
\text { to caries) smooth surfaces in primary } \\
\text { maxillary anterior teeth or DMFS score }>6\end{array}$ \\
\hline \multicolumn{3}{|c|}{ Table 3. Showing Classification of ECC as Formulated } \\
in 1999 at Bethesda
\end{tabular}

\section{Prevalence}

The prevalence of ECC shows a wide variation between different continents and countries. It also varies with several factors like race, culture, ethnicity, socioeconomic status, lifestyle, dietary pattern and oral hygiene habits. Data collected from different parts of the world suggests that in most developed countries the prevalence of ECC is between 1 and $12 \%{ }^{[11]}$ The prevalence of ECC is high in children of families belonging to low socioeconomic categories who also suffer from malnutrition.[12] The prevalence of early childhood caries is highest in Africa and South-East Asia.[13] The prevalence of ECC reported from USA and Europe is comparatively lower than the prevalence in Asia. The prevalence ranged from $11.4 \%$ in Sweden to $7-19 \%$ in Italy.[14] A high prevalence of ECC has been reported from some Middle Eastern countries, such as Palestine (76\%) and the United Arab Emirates (83\%).[15,16] A wide range of variation has been observed in the prevalence reported from various countries such as Greece (36\%), Brazil (45.8\%), India (51.9\%), and Israel (64.7\%).[17-20] According to another study,[21] the highest prevalence of ECC is found in the 3-4 years old age group and boys are significantly more affected than girls.

\section{Risk Factors}

ECC is an aggressive form of tooth decay that begins on tooth surfaces which are usually not affected by decay, such as labial surfaces of maxillary incisors in contrast to dental caries which usually involve plaque retentive areas. Thus, it is thought that there may be distinctive risk factors involved in the progression of ECC.

\section{Microbiological Risk Factors}

The two major bacteria associated with the aetiology of dental caries are Streptococcus mutans and Streptococcus sobrinus.[22,23] These pathogens can produce acids in the presence of carbohydrates like sucrose, glucose or fructose and these acids can dissolve the tooth structures. On average oral bacteria can divide 2-4 times per day [24] and in infants swallowing occur very frequently, so in order to survive the bacteria must become attached to an oral surface. Previous studies have also demonstrated that the ability of $S$. mutans to become attached to epithelial surfaces is very weak. [25] Therefore it can be presumed that these organisms are not able to colonize the mouth of a normal infant before the eruption of teeth.
In children with ECC, $(26,27)$ the population of $S$. mutans is more than $30 \%$ of the plaque flora and it is less than $0.1 \%$ in children having no caries activity. Since mothers are the primary caregiver so transmission of $S$. mutans to the infants is usually from their mothers. The evidence for this concept comes from several clinical studies [28] in which $S$. mutans isolated from mothers and their babies exhibited similar or identical bacteriocin profiles. However, a few incidents of paternal transfer of $S$. mutans have also been reported. Studies have shown that chances of infection is highest when the level of $S$. mutans in mother's saliva is greater than $10^{5}$ colony forming units per ml. [29] Caries causing bacteria can be transmitted from mother or caregiver to child by activities that directly pass saliva, such as sharing a spoon when tasting baby food, cleaning a dropped pacifier by mouth or wiping the baby's mouth with saliva.[30] The chances of bacterial colonization of the oral cavity is highest after the eruption of a tooth.

\section{Feeding Practices}

Improper bottle feeding constitutes an important etiological factor of severe ECC. Several studies have shown a direct relationship between ECC and extended periods of bottle feeding. [31,32] Breast feeding forms the ideal nutrition for infants; but retention of breast milk in the baby's mouth for long periods has shown to result in the production of acids leading to softening of enamel. Increasing the availability of fermentable carbohydrates determine the shift in equilibrium from re-mineralization to demineralization. [33] Studies have also shown that long periods of night-time breast feeding especially after the age of twelve months of age is associated with an increased risk of ECC because saliva production decreases at night which in turn increases the level of lactose in the resting saliva. These factors result in a shift in the balance from re-mineralization to demineralization. Studies have also shown that consumption of sweet beverages at night and delayed introduction of tooth brushing habit, were significant $(\mathrm{p}<0.001)$ predisposing factors for ECC. [34]

\section{Sugars}

There is sufficient evidence which suggest that sugars such as sucrose, fructose and glucose and other fermentable carbohydrates play a vital role in the initiation and progression of dental caries. Sucrose is the most cariogenic sugar because it synthesizes glucan that help the bacteria to adhere firmly to teeth which limits diffusion of acids and buffers in the plaque. Salivary amylase can break down the sugar molecule into smaller components which can be easily metabolized by plaque bacteria.[35] The bacteria produces acidic end products which causes demineralization of teeth and increased risk of caries on susceptible teeth. These acids can persist in the oral cavity for as long as 40 minutes. [36] The risk of ECC increases if sugars are consumed at high frequency and are in a form that is retained in mouths for long periods.[37]

\section{Socioeconomic Factors}

Several studies have shown a close association between ECC and socioeconomic status. ECC is more common in children who live in poor economic condition [38] and who belong to parents of low level of education especially illiterate mothers. Due to the prevailing malnutrition before and after birth the 
risk of enamel hypoplasia increases in these children. Moreover, these children have an insufficient fluoride exposure and the consumption of sugar and other sweets is quite high. ${ }^{[39]}$ Children from low income families tend to make their first visit to the dentist at an older age, less frequently and only when there are established dental problems. In addition, deprived children usually start brushing their teeth later in life.

\section{Environmental Factors}

Dental plaque is the main causative factor of caries. The effective removal of dental plaque forms the basis of caries prevention. Therefore, children should receive oral hygiene instructions soon after the eruption of first primary tooth. In addition, salivary factors like salivary flow rates, antimicrobial properties, buffering capacity of saliva and clearance of food from the oral cavity are also important in reducing the development of caries. As the rate of salivary flow decreases at night, feeding of liquid containing fermentable carbohydrate can increase the caries risk for infants and toddlers. [40] The presence of enamel defects like hypoplasia along with other associated general conditions like preterm birth, low weight at birth, malnutrition and illness can serve as predisposing factors of ECC. [41]

\section{Consequences of Untreated Dental Caries in Children}

The direct consequence of untreated dental caries is pain which affects children's regular activities such as eating, sleeping, talking and playing. Adequate duration of sleep is important for proper functioning of metabolic processes, hormonal processes and regulation of appetite. Lack of sleep can make an individual more susceptible to disease and moreover sleep is also important for recovery from illness. Severe ECC causes chronic pulpitis and this chronic inflammation affects erythropoiesis leading to anaemia. [42] The anaemia caused by chronic disease is also called anaemia of inflammation. Chronic disease may cause certain changes in the red blood cells. These changes can cause early death of the red blood cells and their production is slowed down. In anaemia of chronic disease, the iron that is normally recycled from old RBCs to make new RBC is retained within macrophages. This reduces the amount of available iron needed to form new cells. In addition, there is impairment of iron metabolism within the cells. Severe ECC can lead to the loss of the child's front teeth at an early age which may result in impaired speech development. The early loss of maxillary central incisors may cause incidents of taunting by the child's siblings, peers and family members which often results in poor self-esteem. Severe ECC often requires early extraction of molars which may lead to orthodontic problems in the future. Teeth affected by ECC may need expensive restorative treatments which may cause financial problems in the families of children affected by ECC.[43]

\section{Prevention of Early Childhood Caries}

Several measures have been put forth for the prevention of ECC. Firstly, new and prospective parents should be made aware about ECC and its causes. Secondly, information on ECC should be distributed to new parents from paediatrician's offices, maternity and baby clinics.

\section{Measures for Prevention of ECC}

I. Reducing transmission of cariogenic bacteria from mother to child-

1. This can be accomplished by improving maternal oral health. Maternal stock of cariogenic bacteria can be reduced by application of chlorhexidine $(0.12 \%)$ or fluoride mouth rinses or by using sugar free chewing gums. ${ }^{[44]}$ The mother should be advised to avoid frequent consumption of sugar and sweetened beverages.

2. The transmission of cariogenic bacteria from mother to child can be reduced by avoiding saliva sharing activities like sharing of utensils, food and drinks. The mother or caregiver should avoid the habit of licking a pacifier before giving it to the child.

II. Creating awareness among new and prospective parents about ECC- Child health professionals including paediatricians, physicians and nurses can play an important role in reducing the incidence of ECC. [45] The oral health check-up of the child should be done soon after the child attains one-year age.

III. In children, oral hygiene is a good predictor of future caries. [46] Plaque distribution along the gingival margins can be useful for monitoring the pre-cavitation lesions. Periodic radiographs are very useful in monitoring the inter-proximal caries which may not be visible to the naked eye. Lactobacilli tests are useful to determine the caries activity in an individual and also help to monitor sugar intake.

Revised guidelines of the American Academy of Pediatric Dentistry (AAPD) on ECC.[47]

\begin{tabular}{|l|}
\hline \multicolumn{1}{|c|}{ AAPD Policy Statement on Early Childhood Caries } \\
\hline $\begin{array}{l}\text { 1. Infants should not be put to sleep with a bottle and nocturnal breast feeding } \\
\text { should be avoided after the eruption of first primary tooth. }\end{array}$ \\
\hline 2. Infants should be weaned from the bottle at 12-14 months of age \\
\hline $\begin{array}{l}\text { 3. Frequent consumption of any liquid containing fermentable carbohydrates } \\
\text { from a bottle or no-spill training cup should be avoided. }\end{array}$ \\
\hline $\begin{array}{l}\text { 4. Oral hygiene measures should be initiated from the time of eruption of the } \\
\text { 5. first primary tooth. }\end{array}$ \\
\hline $\begin{array}{l}\text { 6. An oral health check-up is recommended at } 12 \text { months of age to educate } \\
\text { parents and provide anticipating guidance for prevention of dental disease }\end{array}$ \\
\hline Table 4. Revised Guidelines of the AAPD on ECC \\
\hline
\end{tabular}

\section{Fluoride}

Fluoride therapy forms an integral part of the caries preventive strategy. Fluoride is obtained from various sources like fluoridated community water, food processed from fluoridated water and fluoride supplements like fluoridated milk, salt etc. Fluoride is also available in the form of toothpastes, mouth rinses, lozenges, chewable tablets, gels, foams and varnishes. The most easily available and widely used form of fluoride is the fluoridated toothpaste. There is strong scientific evidence which suggests that daily tooth brushing with fluoridated toothpaste is the most effective method of caries prevention. [48] Fluoride exerts its anti-caries action in two ways. Firstly, it replaces hydroxyl ions from hydroxyl apatite and forms fluorapatite which is more acid resistant and secondly, fluoride increases the rate of remineralization. A $30-70 \%$ reduction in caries has been reported from the use of fluoridated toothpastes, mouth wash and topical gel as compared to no fluoride therapy. [49] One word of caution regarding the use of fluoridated dentifrice is that children below four years of age are at risk of dental 
fluorosis of permanent incisors and first molars as they have the habit of swallowing toothpaste. Hence it has been advised that in children below four years of age the amount of toothpaste should not exceed the size of a rice grain or the tip of a pencil eraser. It has also been advised that tooth brushing should be supervised till the child attains seven years of age. Fluoride varnish is a form of topical fluoride which is highly effective in reducing dental caries. It comes in water or solvent based system which dries quickly after application and it maintains a high concentration of fluoride in the demineralised areas for a prolonged period. [50]

\section{Management}

The first step in the management of ECC involves conducting a caries risk assessment for each individual child patient. Children at low risk do not require any restorative therapy. For children at moderate risk preventive measures like topical application of fluoride should be carried out twice a year. For children at high risk cavitated lesions should be stabilised and stability should be monitored till shedding of teeth.[51] Restorative treatment is based on removal of caries and the choice of restorative material depends on the site and extent of decay, child's ability to cooperate and longevity of restoration. The commonly used restorative materials are amalgam, composite, GIC and Resin Modified GIC. If extensive dental treatment is required in a non-cooperative child, then use of GA may be considered. In teeth affected by severe ECC pulpotomy followed by placement of preformed stainlesssteel crown is the treatment of choice.[52] Atraumatic restorative treatment (ART) is a pain free restorative procedure without using LA or any rotary instrument. ${ }^{[53]}$ In ART hand instruments are used for removing caries and Glass Ionomer Cement is used as the restorative material. The major advantage of GIC is fluoride release, chemical adhesion to tooth structure and biocompatibility.

\section{CONCLUSIONS}

ECC is a form of rampant dental caries which affects preschool children and toddlers. This disease exhibits a high rate of prevalence especially among children living in the socially disadvantaged population. Inappropriate feeding practices, frequent consumption of fermentable carbohydrates and lack of tooth brushing habit are some of the major contributing factors of ECC. ECC if left untreated can have a detrimental effect on the overall growth and development of the child. The management of ECC often requires long and expensive dental procedures and may sometimes necessitate tooth extraction at an early age. ECC can be prevented if detected early. Prevention should begin in the pre and perinatal period through the education of prospective and new parents on good oral hygiene and dietary practices.

\section{REFERENCES}

[1] American Academy of Paediatric Dentistry. Policy on early childhood caries (ECC): classifications, consequences and preventive strategies. Oral Health Policies: Reference Manual 2004 - 2005.

[2] Berkowitz RJ. Causes, treatment and prevention of early childhood caries: A microbiologic perspective. J Can Dent Assoc 2003;69(5):304-7.

[3] Van Houte J, Gibbs G, Butera C. Oral flora of children with nursing bottle caries. J Dent Res 1982;61(2):382-5.

[4] Vadiakas G. Case definition, aetiology and risk assessment of early childhood caries: A revisited review. Eur Arch Paediatr Dent 2008;9(3):114-25.

[5] Wyne A. Prevalence and risk factors of nursing caries in Adelaide, South Australia. Pediatr Dent 1999;9:31-6.

[6] Johnston T, Messer LB. Nursing caries: literature review and reporting of a case managed under local anesthesia. Aust Dent J 1994;39(6):373-81.

[7] Ismail AI, Sohn W. A systematic review of clinical diagnostic criteria of early childhood caries. J Public Health Dent 1999:59(3):171-91.

[8] Veerkamp JS, Weerheijm KL. Nursing bottle caries: the importance of a development perspective. ASDC J Dent Child 1995;62(6):381-6.

[9] Drury TF, Horowitz AM, Ismail AI, et al. Diagnosing and reporting early childhood caries for research purposes. A report of a workshop sponsored by the National Institute of Dental And Craniofacial research, the Health Resources and Services Administration, and the Health Care Financing Administration. J Public Health Dent 1999;59(3):192-7.

[10] Congiu G, Campus G, Lunglie PF. Early Childhood Caries (ECC) prevalence and background factors: a review. Oral Health Prev Dent 2014;12(1):71-6.

[11] Ismail AI, Lim S, Sohn W, et al. Determinants of early childhood caries in low income African American young children. Pediatr Dent 2008;30(4):289-96.

[12] Milnes AR. Description and epidemiology of nursing caries. J Public Health Dent 1996;56(1):38-50.

[13] Nobile CGA, Fortunato L, Bianco A, et al. Pattern and severity of early child hood caries in Southern Italy:a pre-school based cross sectional study. BMC Public Health 2014;14:206.

[14] Azizi Z. The prevalence of dental caries in primary dentition in 4-5 year old preschool children in Northern Palestine. Int J Dent 2014;2014:839419.

[15] El-Nadeef MAI, Hassab H, Al-Hosani E. National survey of the oral health of 5-year-old children in the United Arab Emirates. East Mediterr Health J 2010;16(1):51-5.

[16] Oulis CJ, Tsinidou K, Vadiakas G, et al. Caries prevalence of 5,12 and 15 year old Greek children: A National Pathfinder Survey. Community Dent Health 2012;29(1):29-32.

[17] Gomes PR, Costa SC, Cypriano S, et al. Dental caries in Paulinia, Sau Paulo State, Brazil, and WHO goals for 2000 and 2010. Cad Saude Publica 2004;20(3):866-70.

[18] Koya S, Ravichandra KS, Arunkumar VA, et al. Prevalence of early childhood caries in children of West Godavari District, Andhra Pradesh, South India: an epidemiological study. Int J Clin Pediatr Dent 2016;9(3):251-5.

[19] Natapov L, Gordon M, Pikovsky V, et al. Caries prevalence among 5 year old children examined by the school dental 
service in Israel in 2007. Oral Health Dent Manag 2010;9:25-31.

[20] Ramos-Gomez FJ, Weintraub JA, Gansky SA, et al. Bacterial, behavioral and environmental factors associated with early childhood caries. J Clin Pediatr Dent 2002;26(2):165-73.

[21] Nurelhuda NM, Al-Haroni M, Trovic TA, et al. Caries experience and quantification of streptoccosmutans and Streptococcus sobrinus in saliva of Sudanese schoolchildren. Caries Res 2010;44:402-7.

[22] Gibbons RJ. Bacteriology of dental caries. J Dent Res 1964;(Suppl 43):1021-8.

[23] Gibbons RJ, Houte JV. Bacterial adherence in oral microbial ecology. Ann Rev Microbial 1975;29:19-44.

[24] Van Houte J, Gibbs G, Butera C. Oral flora of children with nursing bottle caries. J Dent Res 1982;61(2):382-5.

[25] Berkowitz RJ, Turner J, Hughes C. Microbial characteristics of human dental caries associated with prolonged bottle feeding. Arch Oral Biol 1984;29(11):949-51.

[26] Caufield PW, Wannemuchler YM, Hensen JB. Familial clustering of the Streptococcus mutans cryptic plasmid strains in a dental clinic population. Infect Immun 1982;38(2):785-7.

[27] Caufield PW, Childers NK, Allen D, et al. Distinct bacteriocin groups correlate with different groups of Streptococcus mutans plasmids. Infect Immun 1985;48(1):51-6.

[28] Berkowitz RJ, Jordan HV. Similarity of bacteriocins and Streptococcus mutans from mother and infant. Arch Oral Biol 1975;20(11):725-30.

[29] Berkowitz RJ, Turner J, Green P. Maternal salivary levels of Streptococcus mutans and primary oral infection of infants. Arch Oral Biol 1981;26(2):147-9.

[30] Berkowitz RJ, Jones P. Mouth to mouth transmission of bacterium Streptococcus mutans between mother and child. Arch Oral Biol 1985;30(4):377-9.

[31] Kohler B, Andreen I, Jonsson B. The earlier the colonization by mutans streptococci, the higher the caries prevalence at 4 years of age. Oral Microbiol Immunol 1988;3(1):14-7.

[32] Hallet KB, O'Rourke PK. Early childhood caries and infant feeding practice. Community Dent Health 2002;19(4):237-42.

[33] Azevedo TDPL, Bezerra ACB, de Toledo OA. Feeding habits and severe early childhood caries in Brazilian preschool children. Pediatr Dent 2005;27 (1):28-33.

[34] Van Palenstein HWH, Soe W, van t Hof MA. Risk factors of early childhood caries in a Southeast Asian population. J Dent Res 2006;85(1):85-8.

[35] Ramos-Gomez F, Crystal YO, Ng MW, et al. Caries risk assessment, prevention and management in pediatric dental care. Gen Dent 2010;58(6):505-17.

[36] Jensen ME. Diet and dental caries. Dent Clin North Am 1999;43(4):615-33.

[37] Luke GA, Gough H, Beeley JA, et al. Human salivary sugar clearance after sugar rinses and intake of foodstuffs. Caries Res 1999;33(2):123-9.
[38] Harel-Raviv M, Laskaris M, Chu KS. Dental caries and sugar consumption into the 21st century. Am J Dent 1996;9(5):184-90.

[39] Du M, Bian Z, Guo L, et al. Caries patterns and their relationship to infant feeding and socioeconomic status in 2-4 year old Chinese children. Int Dent J 2000;50(6):385-9.

[40] Maciel SM, Marcenes W, Sheiham A. The relationship between sweetness preference, levels of salivary mutans streptococci and caries experience in Brazilian children. Int J Pediatr Dent 2001;11(2):123-30.

[41] Sukumaran A, Pradeep AS. Early childhood caries: prevalence, risk factors and prevention. Front Pediatr 2017.

[42] Sheiham A. Dental caries affects body weight, growth and quality of life in pre-school children. Br Dent J 2006;201(10):625-6.

[43] Means RT Jr. Recent developments in the anemia of chronic disease. Curr Hematol Rep 2003;2(2):116-21.

[44] Casamassimo PS, Thikkurissy S, Edelstein BI, et al. Beyond the Dmft: the human and economic cost of early childhood caries. J Am Dent Assoc 2009;140(6):650-7.

[45] Kohler B, Andreen I. Influence of caries preventive measures in mothers on cariogenic bacteria and caries experience in their children. Arch Oral Biol 1994;39(10):907-11.

[46] Kohler B, Andreen I. Mutans streptococci and caries prevalence in children after early maternal caries prevention: a follow-up at eleven and fifteen years of age. Caries Res 2010;44(5):453-8.

[47] Gussy MG, Waters EG, Walsh 0, et al. Early childhood caries: Current evidence for aetiology and prevention. J Paediatr Child Health 2006;42(1-2):37-43.

[48] American Academy of Pediatric Dentistry. Policy on Early Childhood caries (ECC). In: Classifications, consequences and preventive strategies. Pediatr Dent vol. 25:7. Reference manual 2003/2004: p. 24-8.

[49] Curnow MMT, Pine CM, Burnside G, et al. A randomised controlled trial of the efficacy of supervised toothbrushing in high caries risk children. Caries Res 2002;36(4):294-300.

[50] Marinho VCC. Evidence-based effectiveness of topical fluorides. Adv Dent Res 2008;20(1):3-7.

[51] Skold-Larsson K, Modeer T, Twetman S. Flouride concentration in plaque in adolescents after topical application of different fluoride varnishes. Clin Oral Investig 2000;4:31-4.

[52] Kindelan SA, Day P, Nichol R, et al. UK National Clinical Guidelines in Paediatric Dentistry: stainless steel preformed crowns for primary molars. Int J Paediatr Dent 2008;(18 Suppl 1):20-8.

[53] Dulgergil CT, Soyman M, Civelek A. Atraumatic restorative treatment with resin modified glass ionomer material: short term results of a pilot study. Med Princ Pract 2005;14(4):277-80 